\title{
Modifying Harmful Beliefs About Academic Setbacks: An Attribution Retraining Intervention for African-American Middle School Students at Risk for Academic Failure
}

\author{
Erin N. Cue $e^{1} \&$ April Z. Taylor ${ }^{2}$ \\ ${ }^{1}$ Psychology Department, Santa Monica College, Santa Monica, California, USA \\ 2 Department of Child and Adolescent Development, California State University Northridge, Northridge, \\ California, USA \\ Correspondence: Erin N. Cue, Psychology Department, Santa Monica College, Santa Monica, California, USA. \\ Tel: 1-310-434-8214.
}

Received: September 3, 2020

Accepted: October 17, 2020

Online Published: November 11, 2020

doi:10.20849/jed.v4i3.799

URL: https://doi.org/10.20849/jed.v4i3.799

\begin{abstract}
Ongoing reports of the achievement gap suggest the need for effective interventions that can increase motivation and academic outcomes for African-American youth. This study describes a 3-week evidence-based attribution retraining intervention designed to alter harmful beliefs associated with academic failure among African-American middle school students. Guided by attribution theory, the lessons in the intervention were designed to help students modify maladaptive attributions for academic failure and understand that positive academic outcomes could be obtained through increased preparation and effort. Participants included $646^{\text {th }}$ graders identified as low achieving who were randomly assigned to either a treatment or wait-list control group. Results showed significant increases in adaptive attributions and decreases in maladaptive attributions for the treatment group compared to the control group. Implications for policy and practice are discussed.
\end{abstract}

Keywords: African-American, motivation, urban education, academic achievement, intervention, middle school, youth, attribution

\section{Introduction}

African American experiences within the U.S. education system have historically been characterized by ongoing mistreatment, inequalities, and the Black-White achievement gap (Boykin \& Noguera, 2011; Darling-Hammond, 2007) with African American students, in particular African American males, consistently and historically lagging behind their non-ethnic-minority counterparts in grade point average and other academic indicators (Ford \& Moore, 2013; Jencks \& Phillips, 1998; Johnson, 2002). Results of national standardized tests over the last five decades have shown that a higher percentage of African American students score below their peers in reading and mathematics achievement and that this gap increases between African American and Whites during the transition from elementary to middle school (United States Department of Education, 2009a, 2009b, 2015).

A wealth of research links African-American students' academic underperformance with a number of macro-level factors including low socioeconomic status, poor performing schools, and low parental involvement (see Barton, 2003; Darling-Hammond, 2007) and efforts to address these outwardly observable, if complex, factors related to educational inequities has yielded limited gain. We argue that these efforts can be augmented by increased consideration of micro-level factors including students' own perceptions and attitudes. To illustrate, there is a documented relationship between African-American students' perceptions of achievement and academic outcomes in that, for example, African-American students labeled as gifted are more likely to exhibit belief in the "American Achievement Ideology" - the notion that working hard in school will result in long-term gain, than are non-gifted identified African-American students (Ford, 1992; Irving \& Hudley, 2008; Ogbu, 1991). This belief, in turn, has been associated with positive behavior and effort in school and students' positive beliefs in their own academic achievement and future outcomes related to their education (Ford, 1992; Sanders, 1998). Despite evidence for a proximal relationship between academic attitudes and outcomes, very little research has explored the potential of African-American students' own personal attitudes and beliefs regarding their experienced academic (under)achievement as a vehicle to impact achievement outcomes (see Barton, 2003 and 
Darling-Hammond, 2007 for exceptions). In this study, we assess the effectiveness of a culturally relevant, attribution theory guided, school-based intervention for urban African-American middle school students. The specific goal of the intervention was to adaptively modify students' beliefs regarding academic achievement and thereby improve students' academic behaviors and outcomes.

\subsection{Attribution Theory and the Link Between Achievement-Related Cognition and Behavior}

Attribution theory outlines a cognitive sequence that individuals undergo in response to an unexpected or undesirable event, and is therefore a useful theoretical framework for examining the relationship between perceived causes of academic failure and subsequent achievement expectations, behaviors, and outcomes (Weiner, 2000). Attributions are answers to why questions; for example, in the academic domain one might ask, "Why did I fail the exam?" or, "Why didn't I pass that class?" The causal attribution or reason an individual provides for why certain events or outcomes occur can vary widely (e.g., I'm not smart enough, I couldn't focus, the teacher is biased...etc.; Weiner, 1985). Rather than focus on a given reason or cause per se, attribution theorists examine the underlying properties of causes. There are three properties, or dimensions, on which any stated cause can be classified: (1) locus, whether the reason is either internal or external to the individual; (2) controllability, whether the cause is determined by volitional influence or not; and (3) stability, whether a cause can change over time or is expected to remain constant (Weiner, 1995; 2000). All causes are theoretically classified into one of the eight cells of a locus X stability X controllability matrix.

In U.S. culture the most frequently reported causes of academic success or failure are ability (e.g., "I failed the test because I was not smart enough") and effort (e.g., "I failed the exam because I did not try hard enough") (Graham \& Weiner, 1993; Weiner, 1985). Due to their underlying causal properties, ability and effort are each associated with distinct psychological and behavioral outcomes (Weiner, 1985; 2000). Ability is typically perceived as internal, stable, and controllable. When we attribute failure to low ability, we tend to see this outcome as a characteristic of ourselves, enduring over time, and beyond personal control - according to attribution theory the emotional-behavioral consequence of this attribution is discouragement and resignation. Effort is also internal but, unlike ability, is unstable and controllable - a state rather than a trait and one that is modifiable by one's own volition. The typical emotional-behavioral consequence of a failure due to lack of effort is hope and to try harder in the future. In failure situations, attributions to lack of ability (stable, uncontrollable) are motivationally maladaptive (associated with decreased motivation, performance, and participation) whereas attributions to lack of effort (unstable, controllable) are motivationally adaptive (associated with high achievement striving, academic performance, motivation, persistence, and task participation; Weiner, 1995; 2000). As such, attribution retraining interventions have been utilized in an effort to modify students' beliefs about their academic failure outcomes from stable (i.e., ability) to unstable causes (i.e., effort). The overall findings of most attribution retraining interventions indicate that by increasing students' adaptive thoughts, researchers can also improve students' achievement outcomes (see reviews in Haynes, Perry, Stupnisky, \& Daniels, 2009; Robertson, 2000; Wilson, Damiani, \& Shelton, 2002).

\subsection{An Attributional Approach to Understanding Motivation Among African-American Youth}

Due to the rich framework it provides, researchers have expressed that attribution theory may be extremely useful in addressing low academic achievement and motivation among ethnic-minority youth (Graham, 1994; van Laar, 2000). Research supports a link between causal stability, expectancy, and achievement among African American students in particular (Graham, 1984; Willig, Harnisch, Hill \& Maehr, 1983). For example, Graham (1984) and Willig et al., (1983) found that low ability (a stable attribute) was associated with low expectancy, low persistence, test anxiety, and low math achievement for African American students. Graham (1984) also revealed socioeconomic differences in that African American students from middle-SES groups were more likely to attribute their failures to lack of effort than African American students for low-SES groups and White students from both low- and middle-SES groups. A more recent study showed changes in attributions across time, such that African American students were more likely to attribute their academic failure to low ability across the transition from middle- to high-school and that these attributions had impacts on future classroom engagement (Swinton, Costes, Rowley \& Okeke-Adeyanju, 2011).

Additionally, although only a few attribution retraining interventions have targeted African American students, researchers have also found support that attributional retraining interventions could be effective in improving African American youth's academic and behavioral outcomes (e.g., Aronson, Fried, \& Good, 2002; Blackwell et al., 2007). Based on a comparative analysis of the effects of attribution retraining programs, researchers have reported more improvement in African Americans students' academic performance, engagement, and school identification compared to that of white students following participation in an evidence-based attribution 
retraining intervention (e.g., Aronson et al., 2002). Similarly, results of attribution retraining interventions using majority African American populations indicated positive effects on youths' academic competence, motivation, and persistence, and increased likelihood to attribute academic failure to a lack of effort (an adaptive attribution) versus ability (Hudley, 2001; Graham, Taylor, \& Hudley, 2015).

The interventions mentioned above have obtained positive results by focusing on the four main causal attributions (i.e., ability or aptitude, effort/strategy, luck, and difficulty of the task). However, despite their presumed relevance, no studies to our knowledge have examined the role of culturally specific attributions, such as attributions to discrimination, which have been identified as relevant to the experiences of African-Americans or otherwise stigmatized groups (Graham \& Hudley, 2005; Major, Quinton, \& Schmader 2003). It is reasonable to assume that attributions to discrimination would be associated with academic failure for ethnic minority students, since African-American students are more likely than their white counterparts to report experiencing discrimination in school and these experiences have been found to be associated with academic disengagement (Seaton, Caldwell, Sellers, \& Jackson, 2008; Smalls, White, Chavous \& Sellers, 2007; Wong, Eccles \& Sameroff, 2003).

\subsection{Current Study}

The current study investigated the beliefs that African-American students transitioning to middle school held concerning the causes of their academic failure and explored whether maladaptive beliefs could be altered through a brief culturally-adapted attribution theory based retraining program. It was argued that reframing African-American students' perceptions of academic failure towards motivationally adaptive attributions would have a positive impact on education-related outcomes. In addition, we investigated to what extent the attribution retraining intervention was useful in altering attributions to discrimination, a less explored causal ascription that may be particularly relevant to African-American youth.

Attribution theory is especially appropriate in that it not only outlines a motivational sequence which connects the reasons students give for their failure to relevant psychological and behavioral outcomes, it also offers a model for social-psychological interventions which have demonstrated success modifying students' harmful beliefs, increasing adaptive beliefs and improving academic performance (e.g., Good et al., 2003; Wilson \& Linville, 1982, 1985). We used attribution theory as our guiding framework for studying African American middle school students' beliefs about academic setbacks and for the intervention specifically designed to alter maladaptive beliefs among this group.

Researchers have described transition periods as the most fitting time to pursue attributional retraining interventions because it is at this time that students are less aware of what to expect and therefore more open to a reframing of perception (Perry, Stupnisky, Hall, Chipperfield, \& Weiner, 2010). The transition to middle school is particularly characterized by a decrease in academic performance, school liking, and academic motivation for students of all races (Anderman, Maehr, \& Midgley,1999; Simmons, Black \& Zhou, 1991; Steele, 1992; Wigfield, Lutz \& Wagner, 2005). In addition to being characterized by an increasing race-based achievement gap, research shows that the middle school transition can be a decisive period for African-American youth's achievement and motivation, especially for African-American males who are at an even greater risk for academic failure compared to their African American female and non-ethnic minority counterparts (Taylor \& Graham, 2007; Yaffe, 2012). Although most attributional retraining programs to date have been administered during the transition to college, studies have shown that these programs can also be successfully implemented during the critical transition to middle school (Blackwell, Trzesniewski, \& Dweck, 2007; Good et al., 2003), the period on which this study focuses.

\section{Method}

\subsection{Recruitment and Selection of Participants}

Participants were recruited from three public middle schools situated within low-income urban settings in the greater Los Angeles area. Each middle school was selected because their student population included a large percentage of African-American students (50\% or more), and more than half of the students received free/reduced lunch, an indicator that schools were located in lower income neighborhoods (Caldas, 1993; Ensminger et al., 2000).

Approximately 520 students were recruited in their homeroom during the beginning of their $6^{\text {th }}$ grade year. The ethnic breakdown of these students was 55\% African-American, 39\% Latino, 4\% White, and 2\% who were classified in school records as "other." Parental consent forms that explained the purpose of the study and guaranteed confidentiality were distributed to students across the three schools. 
All students who returned a signed consent form $(n=306)$ were invited to complete a pre-questionnaire which asked students about their current grades and attributions for failure. Students reported their current grades in mathematics, English, history, and science. Each student's GPA was later calculated using the average of the four grades on a 4.0 rating scale $(1=D, 4=A)$. Attributions for failure were captured by an attribution questionnaire in which students were asked to recall the last time they did poorly on a test and to explain what caused this outcome by rating a set of attributions as possible reasons for their failure.

Participants for the intervention were selected from the 168 African-American $6^{\text {th }}$ graders $(76$ males and 92 females) who completed the pre-questionnaire. Intervention participants were recruited based on the following criteria obtained from the pre-questionnaire data: 1) GPA below the sample median, 2) scoring below the sample mean for endorsing attributions to lack of effort (the desired attribution for this study), and 3) above the sample mean for attributions to low ability, external factors, or discrimination. In sum, students selected for the intervention were identified as low-achieving African American students who were less likely to attribute failure to lack of effort and more likely to attribute failure to stable or external causes. A total of 65 students met the eligibility criteria ( 37 females and 28 males). All students selected for the intervention agreed to participate, except for one male who had a scheduling conflict. Thirty-one participants were randomly assigned to the experimental group and 33 were assigned to the waitlist-control group.

\subsection{Intervention Implementation and Curriculum}

The attribution retraining program took place during lunch twice a week for three weeks. Each lesson lasted 20 -minutes and consisted of groups of 8-10 students. The number of students in each group, the number of sessions per week, and the duration of the current study were modeled after successful attribution retraining interventions conducted in middle schools (Vaughn, Denton \& Fletcher, 2010; Blackwell et. al., 2007).

In the current study, students in the experimental group participated in an effort-attribution focused intervention that was introduced as a program designed to encourage $6^{\text {th }}$ graders to begin thinking about goal setting. The lessons in the intervention were aimed at helping students understand that positive academic outcomes (such as reaching their future goals and improving their current grades) can be obtained through preparation and effort. The students also were taught that academic failure was only a temporary setback that could be avoided in the future with adequate preparation. These messages were relayed to the students through lessons on taking personal responsibility for achievement, practice with effort strategies (such as goal setting), the sharing of personal experiences of peers and same-race college students, and learning about prominent figures in the media that overcame setbacks. Guided by recommendations from attribution-retraining studies designed specifically for African-American students, the current study consisted of lessons that were culturally sensitive (e.g., Graham, et al., 2015). In addition, culturally relevant components were also included, such as the interactions with same-race college and peer role models. Research suggests that mentor-mentee similarity (e.g., cultural and/or ethnic background) can be useful in helping students connect and relate to the messages provided by mentors, and that these connections are conducive to feelings of trust and bonding (Lee, 1999). The intervention was divided into three major components and included application assignments, and fidelity checks.

\subsubsection{Component 1: Introduction to the Program (1 Lesson)}

The first component of the intervention introduced students to the program and helped them to begin thinking about their future goals and how their goals were connected to their current schooling. Goal setting is a known effort strategy that has been found to be useful in motivating students to sustain effort (Bandura, 1997; Graham, Taylor, \& Dolland, 2003). In this lesson students identified personal aspirations for the future and created related short-term goals that would help them obtain their long-term or future career goals. Over the course of the intervention, students revisited and verbally reported their progress on their short-term goal to the group.

\subsubsection{Component 2: Attribution Retraining (2 lessons)}

The second component of the intervention focused on identifying personal attributions for failure and modifying attributions for academic failures to unstable causes (e.g., lack of effort) rather than stable causes (e.g., low ability) Students were taught that at some point all students fail, do poorly, or fall short of meeting a goal, and that how they approach or view this failure outcome has an effect on their future outcomes. In these lessons students defined effort and generated effort strategies that they could use in their classes to reach their short-term goals (e.g., asking the teacher for help, trying harder on homework assignments). Overall, in this component, students were taught that through increased effort and hard work they could obtain their goals and prevent undesirable outcomes. 


\subsubsection{Component 3: Positive Same-Race Examples (3 Lessons)}

In the final component of the intervention same-race role models in the media, college students, and peers provided positive real-life examples of how setting goals, attributing failure to effort, and using effort strategies could help the students obtain their future goals and achieve better academic outcomes. For example, during the last session, local college students participated on a speaking panel, where they shared their personal experiences of overcoming obstacles and failure through increased effort. In addition, students in the intervention shared their own stories of how, over the course of the program, their increased effort helped them obtain their short-term goals. Real-life examples were used to illustrate to students that there are other same-race individuals with similar backgrounds that have overcome academic failure and obstacles to success.

\subsubsection{Self-Application Assignments}

At the end of each lesson, students were given a self-application assignment to complete outside of the intervention. These assignments consisted of either a brief task or question that was used to encourage students to continue thinking about the material they had just learned. At the beginning of each new lesson, students were asked to share their answers to the previous week's self-application task. Examples of self-application assignments included, employing school success strategies (such as goal setting) in their actual classrooms and working towards the completion of the short-term goals they had created in (see 2.2.1). Goal setting has been identified as a strategy that is useful in gauging progress and sustaining motivation (Bandura, 1997; Graham, 2016). Previous attribution retraining studies have documented that using self-application assignments helped students to practice and retain skills introduced in experimental programming (Aronson et al., 2002). In addition, other research has shown that many students in early adolescence learn or remember information better when they can put the knowledge they have gained into action or apply it to their own lives (Freire, 2000).

\subsubsection{Fidelity Checks and Evaluation}

Additionally, procedure checklists were filled out after each lesson and at the end of the last session students were asked to complete an anonymous evaluation of the program. Research assistants completed the procedure checklist to assess consistency in the delivery of each lesson, to ensure that all components of the lesson were completed, and to report on students' engagement during the lesson. Checklists were reviewed at the end of each week to confirm that every intervention group received the same materials and lessons. The evaluation distributed at the end of the intervention allowed students the opportunity to rate how much they liked the program, what they learned from the program, and their level of involvement in the program. Students were also asked to rate their understanding of the lessons and their experience with their group leader.

\section{Measures}

Data from both the experimental- and wait-list control groups were collected at three time points: before the intervention (i.e., pre-questionnaire/screening), one week following the intervention (i.e., post-questionnaire), and, to study potential long-term effects of the intervention, six weeks after the post-questionnaire (i.e., follow-up questionnaire). All questionnaires were identical and assessed students' causal attributions for academic failure, and psychological and behavioral outcomes through a combination of self- and teacher-reported measures.

\subsection{Causal Attributions}

Attributions for failure were captured by a modified version of the attributional questionnaire utilized in Graham, et al., (2003). In this measure, students were asked to write about the last time they did poorly on a test and to explain what caused this outcome. After writing about their experience, students were asked to rate a set of attributions as possible reasons for their failure. These attributions included 11 items that assessed four attributional factors: low ability (e.g., "I'm just not smart enough," $\alpha=.73$ ), lack of effort (e.g., "I should have studied more," $\alpha=.59$ ), external factors (e.g., "The stuff I studied wasn't on the test," $\alpha=.59$ ), and discrimination (e.g., "The teacher didn't like me, because of my race/ethnic group," $\alpha=.67$ ). Each item was rated on a 5-point Likert scale $(5=$ definitely a reason, $1=$ definitely not a reason $)$.

Following these attributions, students were asked to identify the single most important explanation for their academic failure. This could include one of the causal attribution items provided or any additional reason to which they attributed their poor performance.

\subsubsection{Psychological Outcomes}

Measures of future expectations and hope were used to assess students' beliefs and emotions related to their academic achievement and future goals. Attribution theorists have hypothesized that psychological factors such as 
hope and future expectations of success mediate the relationship between causal attributions and behavioral outcomes (Weiner, 2000).

Future expectations. Students' future expectations were measured using a modified version of the Children's Future Expectation Scale (Wyman, Cowen, Work \& Kerley, 1993). This measure included four items (e.g., "How sure are you that you will get good grades in middle school?") rated on a 5-point Likert scale ( $1=$ not at all sure, 5 $=$ very sure, $\alpha=.72$ ).

Hope. Students' belief that they were in control and able to sustain paths to desired goals was measured by the Children's Hope Scale. This measure consisted of six items (e.g., "Even when others want to quit, I know that I can find ways to solve the problem," $\alpha=.81)$ rated on a 6-point Likert scale $(1=$ none of the time, $6=$ all of the time; Snyder et al., 1997).

\subsubsection{Behavioral Outcomes}

Several behavioral measures were used to evaluate students' achievement, behavior, and performance in the classroom. These measures included self-reported academic performance and engagement as well as teacher ratings of engagement and persistence.

Academic performance. Academic performance was measured by each student's current grade point average (GPA). Students indicated their current grades in mathematics, English, history and science. GPA was calculated using a 4.0 rating scale $(1=D, 4=A)$.

Engagement. Self-reported engagement was measured with four items developed by the Institute for Research and Reform in Education, Inc. (IRRE, 1998). Students were asked to respond to items such as, "I work very hard on my schoolwork" $(1=$ very true, $4=$ not at all true $; \alpha=.77)$.

Teacher ratings of engagement. Teachers rated each student's engagement in the classroom (e.g., "In my class this student concentrates on doing his/her work") using the Teacher Report of Engagement Questionnaire (Wellborn \& Connell, 1991). This measure included six items rated on a 4-point Likert scale $(1=$ never, $4=$ always; $\alpha=.89)$.

Teacher ratings of persistence. To determine how tenacious students were in class, teachers reported on each student's persistence. Persistence was captured with three items (e.g., "Student gives up easily on schoolwork") that were based on a measure used by Graham, et al., (2003). Teachers rated each item on a 4-point scale $(1=$ never; $4=$ always; $\alpha=.83$ ).

\section{Results}

To test effects of the intervention, three separate data analyses were completed. First, to examine the effects of the intervention on students' causal attributions for academic failure, independent repeated-measure analyses of variance (ANOVAs) were conducted. A 2 (Treatment) X 2 (Time) X 2 (Gender) ANOVA with repeated measures on the second factor (i.e., time) was conducted for each causal attribution to determine changes in causal attributions from pre-questionnaire to post-questionnaire and, to explore possible lagged-effects, from pre-questionnaire to follow-up questionnaire. The same analyses were also used to test whether the intervention had an impact on psychological (i.e., future expectations, hope) and behavioral outcomes (i.e., academic performance, engagement, persistence), which were also measured at each time point.

Second, experimental and control groups' responses to the open-ended question about their primary reason for academic failure were compared to detect qualitative change in adaptive and/or maladaptive causal attributions over time. Lastly, an analysis of students' evaluation of the current program was conducted to measure the social validity of the study including acceptability, importance of intervention effects, and student participation.

As stated previously, survey data were collected from all students one week prior to the intervention (pre-questionnaire), one week following the intervention (post-questionnaire) and six weeks after the post-questionnaire (follow-up questionnaire). Preliminary analyses showed no significant differences between the experimental and waitlist control groups on the pre-questionnaire on any of the analyzed variables including causal attributions and psychological and behavioral outcomes (all $p$ s ranged from .13 to .23). 
Table 1. Experimental and control group pretest scores

\begin{tabular}{lllll}
\hline & \multicolumn{2}{l}{ Experimental Group } & \multicolumn{2}{l}{ Control Group } \\
\hline Variable & $\mathrm{M}$ & $\mathrm{SD}$ & $\mathrm{M}$ & $\mathrm{SD}$ \\
\hline Causal Attributions & & & & \\
\hline Lack of Effort & 3.36 & .94 & 3.31 & 1.07 \\
\hline Lack of Ability & 2.79 & .86 & 2.58 & 1.09 \\
\hline External Attribution & 2.44 & 1.21 & 2.37 & 1.21 \\
\hline Discrimination & 2.16 & 1.34 & 1.70 & 1.07 \\
\hline Psychological Outcomes & & & & \\
\hline Hope & 4.30 & 1.20 & 4.66 & 1.09 \\
\hline Future Expectations & 4.46 & .43 & 4.51 & .59 \\
\hline Behavioral Outcomes & & & & \\
\hline Student Engagement & 3.27 & .45 & 3.36 & .56 \\
\hline GPA & 2.09 & .81 & 2.13 & .78 \\
\hline Student Engagement & 2.24 & .81 & 2.33 & .83 \\
\hline Persistence & 2.78 & .83 & 2.79 & .93 \\
\hline
\end{tabular}

Table 1 presents the descriptive data for all pre-questionnaire variables used in the analyses by group.

\subsection{Intervention Effects}

\subsubsection{Causal Attributions for Academic Failure}

Separate 2 (Treatment) X 2 (Time) X 2 (Gender) repeated-measures ANOVAs were carried out to test changes in each causal attribution immediately after the intervention (i.e., pre- to post-questionnaire) as well as at six-weeks after the intervention (i.e., pre-questionnaire to follow-up). Effect sizes for each significant interaction were calculated with Cohen's $d$. These effect sizes were interpreted using Cohen's (1988) guidelines for interpretation (i.e., 80 or higher indicated a large effect size, .50 a moderate effect size, and .20 a small effect size).

Results showed no significant effects of the intervention on any of the causal attributions at the time of the post-questionnaire (i.e., lack of effort: $(F(1.56)=1.54, p=.22)$; lack of ability: $(F(1,58)=1.50, p=.23)$; discrimination: $(F(1,58)=.14, p=.71)$; external attributions: $(F(1,58)=.99, p=.32)$. These results suggest that students' causal attributions for academic failure were not altered by the intervention immediately following completion of the intervention.

However, significant results were found in the repeated-measures analyses comparing pre-questionnaire to follow-up data (collected six weeks after the post-questionnaire). Results of these analyses indicated a significant three-way interaction for attributions to lack of effort $(F(1,52)=4.00, p=.05)$ and a three-way interaction for attributions to discrimination that approached significance $(F(1,53)=3.07, p=.09)$. (Note 1) Specifically, for the variables lack of effort and discrimination, the effect of the intervention across time differed for males compared to female as is described below.

Lack of effort. The 2 (Treatment) X 2 (Time) repeated-measures ANOVAs between gender indicated a near-significant two-way interaction on lack of effort - but only for boys $(F(1,23)=3.68, p=.06)$. As seen in Figure 1, the significant three-way interaction for lack of effort was generated primarily by a different pattern of change across time for males compared to females. For boys in the experimental group attributions to lack of effort increased from pre-questionnaire to the 6-week follow-up, $t(26)=-2.03, p=.05, d=.64$, whereas boys in the control group showed no significant difference in effort attributions during this time, $t(12)=.73, p=.48$. In contrast, there were no significant effects of the intervention on lack of effort attributions for girls in the experimental or control group. 

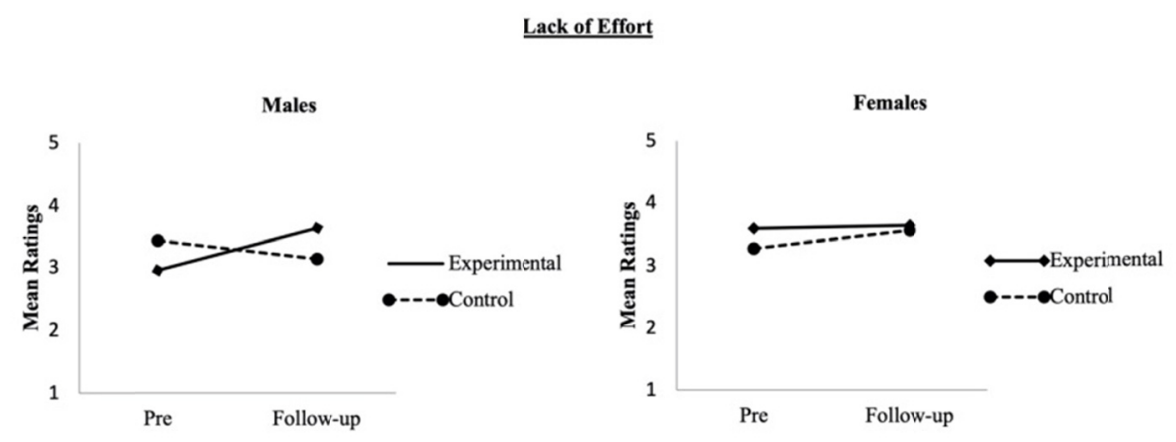

Figure 1. Lack of effort attributions endorsed by experimental and control group at pretest and follow-up by gender

Discrimination. Similarly, the 2 (Treatment) X 2 (Time) repeated-measures ANOVA within gender trended towards an interaction for attributions to discrimination for boys, $F(1,24)=2.97, p=.09$, and not females (see Figure 2).

Experimental boys were less likely to attribute their academic failure to discrimination at the follow-up questionnaire, $t(27)=1.35, p=.07, d=.56$, than were boys in the control group who were more likely to attribute their academic failure to discrimination during the follow-up questionnaire, $t(12)=-.75, p=.47$. No change was found for both experimental and control girls on attributions to discrimination from pre-questionnaire to follow-up.

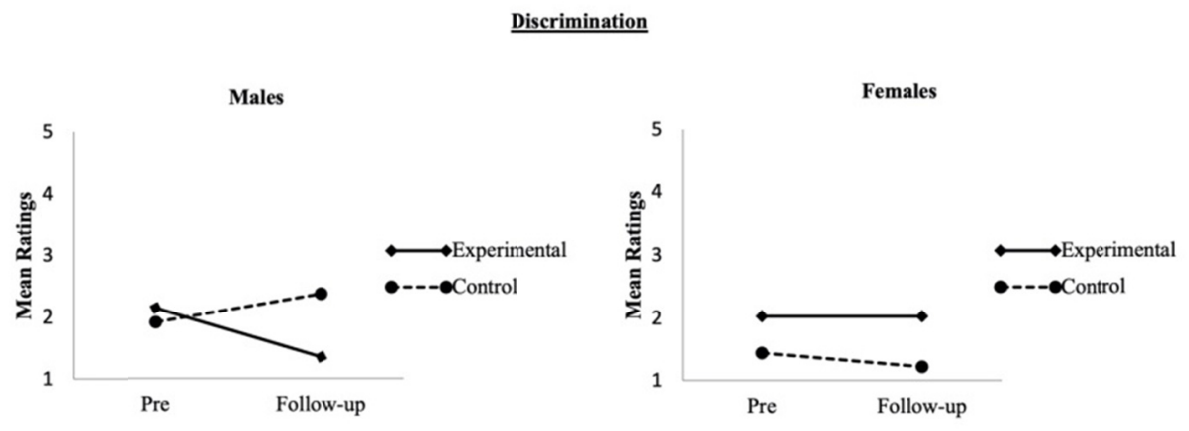

Figure 2. Discrimination attributions endorsed by experimental and control group at pretest and follow-up by gender

No main effects or significant interactions were found for lack of ability $(F(1,54)=.01, p=.94)$ or external attributions $(F(1,54)=.23, p=.63)$. Overall, the results of these analyses indicated that the goals of the attribution retraining intervention were partially upheld. Lagged effects showed that for boys in the experimental group, adaptive unstable attributions (i.e., lack of effort) increased and maladaptive attributions (i.e., discrimination) trended towards decreasing however no such change was found among girls in the intervention.

\subsubsection{Psychological and Behavioral Outcomes}

Separate 2 (Treatment) X 2 (Time) X 2 (Gender) repeated-measures ANOVAs were used to test whether the intervention had an impact on psychological and behavioral outcomes. Results of these analyses indicated no significant differences at Time 2, immediately after the intervention (i.e., pre- to post-questionnaire), nor Time 3, six weeks after the post-questionnaire (i.e., pre-questionnaire to follow-up). Specifically, no interaction effects were found for the following psychological and behavioral outcomes at Time 2 and Time 3, respectively: hope: $F(1,58)=2.88, p=.10, F(1,54)=.02, p=.90$; future expectations: $F(1,56)=.02, p=.89, F(1,52)=1.49, p=.23$; student engagement: $F(1,57)=.08, p=.79, F(1,53)=.09, p=.76$; GPA: $F(1,57)=.04, p=.84, F(1,53)=.01, p$ $=.93$; teacher ratings of engagement: $F(1,50)=.53, p=.47, F(1,51)=.20, p=.66$; and teacher ratings of 
persistence: $F(1,52)=.36, p=.55, F(1,51)=.71, p=.41$. These findings suggest that the brief attributional retraining intervention did not impact students' psychological and behavioral outcomes as operationalized in this study.

\subsection{Open-Ended Responses to Primary Reason for Academic Failure}

To further test students' change in attributions for failure, their answers to an open-ended question that asked them to identify the single most important reason for their academic failure was transcribed and content analyzed. Students completed this question after completing the 11 attributional ratings in the causal attribution questionnaire at each time point. Verbatim responses to the open-ended questions were coded into categories based on the four main causal attributions identified in the current study (i.e., ability, effort, external, and discrimination). In addition to these causal attributions, a very small percentage of students selected attributions that could not be labeled as one of the four categories. These attributions were identified as "other" (e.g., "I wasn't there that day").

Using students' responses to this open-ended causal attribution question, the percent change in frequency was examined from pre-questionnaire to the follow-up questionnaire for both the experimental and control group. If the intervention was effective, it would be expected that experimental students' attributions for lack of effort would increase over time. Figure 3 shows the percentage of students who chose each of the causal attributions at each time point by treatment group.
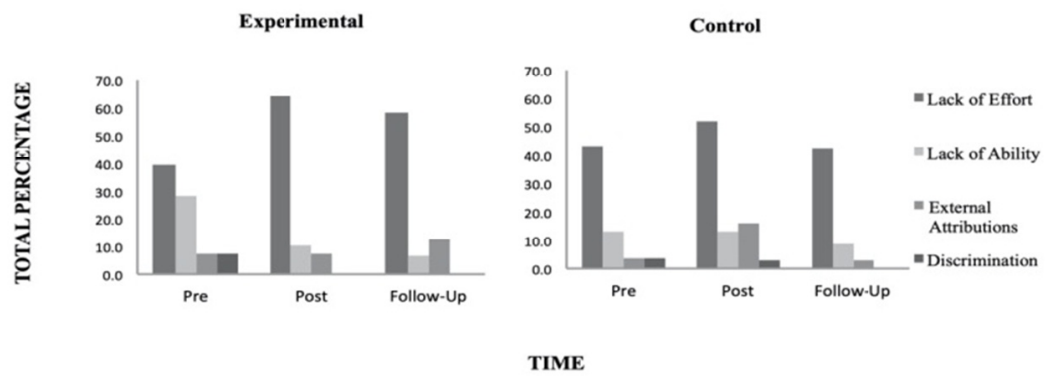

Figure 3. Percentage totals for each causal attribution by treatment group

Note. Responses identified as other are not included in Figure 3

As shown in Figure 3 (left panel), as predicted for the experimental group, from pre-questionnaire to post-questionnaire, attributions to lack of effort increased by 23 percentage points, whereas attributions to lack of ability decreased by 16 percentage points and these margins were maintained or widened from post-questionnaire to the follow-up questionnaire. In contrast, for the control group (Figure 3 right panel), adaptive attributions to lack of effort increased on average by only 6 percentage points from pre-questionnaire to post- and follow up and maladaptive attributions to lack of ability remained the same across time. In general, these findings suggest that the experimental group showed both positive immediate and long-term improvement relative to the control group that experienced relatively slight attributional change. Attributions to external causes were erratic and those to discrimination were too infrequent to allow analysis.

\subsection{Student Evaluation of the Program}

Since one of the goals of the study was to investigate if evidence-based strategies used in attribution retraining interventions are amenable to African-American students struggling with the critical transition to middle school, the study also included analysis of student evaluation surveys of the program. The intention of these surveys was to provide students' perceptions of the social validity of the program, which included treatment acceptability and engagement in the program. Specifically, students were asked to answer questions related to how much they liked the program, skills acquired, and opportunities to apply the skills learned to other settings. All but one student who received the intervention completed the student evaluation. Of these students, $93 \%$ indicated that they liked being in the program. In addition, over $90 \%$ of students revealed that they completed the additional activities outside of the group and that they were willing to complete the program again. Ninety-percent of the participants also indicated that the program made a difference in their grades (i.e., $43 \%$ rated a little, $47 \%$ rated a lot). Over $80 \%$ of 
students also noted that they learned important skills that will help them do better in school (e.g., built confidence, helped change grade). Additionally, $70 \%$ of the students identified that the program was easy to follow and that they would recommend this program to a friend.

\subsection{Summary of Findings}

The primary focus of this intervention was to increase adaptive attributions (e.g., lack of effort) and decrease maladaptive attributions towards academic failure (e.g., lack of ability, external attributions, discrimination). Although results did not show decreases in all maladaptive casual attributions, a trending decrease in attributions to discrimination and an adaptive increase in attributions to lack of effort 6-weeks after the intervention was evident for boys. In other words, this brief intervention was able to change maladaptive attributions among low achieving African-American males. In terms of psychological and behavioral outcomes, the intervention did not prove powerful enough to effect change.

Intervention students' qualitative report on their beliefs regarding the most salient reason for their academic failure showed adaptive change from pre- to follow-up questionnaire in that their attributions to lack of effort increased over time. In addition, student evaluation surveys provided support of positive intervention experiences for program participants.

\section{Discussion}

This study reports the efficacy of a culturally-adapted attribution retraining intervention for African American $6^{\text {th }}$ graders at risk for academic failure. Although previous research using minority samples suggests that the evidence-based strategies used in attribution retraining interventions could also be beneficial in increasing academic achievement and motivation among African-American youth (e.g., Good et al., 2003), there have been only a few attribution retraining interventions that have concentrated on this population of students (see Hudley, 2001; Graham, et al., 2015 for exceptions). Furthermore, to our knowledge there has been no culturally-adapted attribution retraining interventions that focused specifically on African-American students during the critical transition to middle school.

Data from this randomized attribution retraining study provides some evidence that the strategies in these brief social-psychological interventions can be used to alter undesirable attributions about academic failure among African-American youth during a period of their educational journey that is faced with many challenges. Previous attribution retraining studies for African-American youth have shown increases in attributions to lack of effort (e.g., Hudley, 2001), the present study adds to this literature by providing evidence that attributional retraining interventions can also be useful forums for modifying harmful attributions that are salient to many academically at-risk students yet previously unexplored within these programs, such as ascriptions to discrimination.

Being able to alter attributions to discrimination is particularly important for African-American youth because many students within this population report experiencing unjust treatment, which has been shown to have negative effects on their psychological well-being and academic performance (Wong et al., 2003). It has been suggested that the external properties of discrimination may be helpful to African-American youth's self-esteem because it acts as a self-protective mechanism, and students are able to attribute their academic failure to something other than themselves (Crocker \& Major, 1989). It has also been argued that, if considered stable by African American youth, (for example due do endured experiences or parental socialization), attributions of discrimination could be detrimental (Hughes et al., 2006; van Laar, 2000). This latter perspective is consistent with attribution theory which also discourages external attributions to the extent that they inhibit the sense of agency. Students in the current intervention were encouraged not to succumb to these beliefs, but to overcome perceived discrimination by continuing to put forth effort and disproving negative stereotypes that may be associated with their group.

This study yielded intriguing findings regarding gender. As hypothesized, males in the experimental group increased in their ascriptions to the more adaptive attribution, lack of effort, while simultaneously decreasing their attributions to discrimination. It is unclear why these intervention effects were found among African-American males yet not females. Some researchers have proposed that an effective curriculum for African-American males in particular engages them in meaningful activities, incorporates material they are able to connect with, and allows them to discuss real issues (Howard, 2014; Tatum, 2005). Hence, the use of many of these elements in the present intervention may have added some novel appeal that resonated with males more so than females. For example, students in the intervention had the opportunity to discuss reasons for their academic failure, as well as learn about popular African-American male figures that faced challenges before achieving success in their careers (including then-President Barack Obama). Another possibility is that the messages provided in the study may have been new to males. Wilson and Linville (1985) proposed that the stronger effects for males in their study were due to females being more prone to discover the messages presented in the intervention on their own before the intervention could 
be completed.

Qualitative findings on students' primary reason for academic failure and perceptions of the intervention support the previous literature suggesting that attribution retraining interventions could be beneficial in modifying attributions for African-American youth at risk for academic failure. Content analysis showed that, after the intervention, both boys and girls in the experimental group were more likely to endorse lack of effort and less likely to attribute failure to maladaptive attributions (i.e., lack of ability, discrimination, and external attributions). Furthermore, student evaluation surveys suggested that students perceived additional positive intervention effects and improvement in their academic behavior. Overall, survey reports showed that a majority of the students who participated in the intervention indicated that they liked the program, the program made a difference in their grades, and they learned important skills to help them do better in school. The fact that intervention effects regarding social validity and treatment acceptability were perceived positively by intervention participants at-risk for academic failure is an additional strength. Although not always reported in the literature on school-based interventions for at-risk youth, acceptability is an important aspect to consider when designing interventions for African American children and is often correlated with the effectiveness of and participant compliance with the intervention (Kratochwill \& Stoiber, 2000).

\subsection{Limitations}

As with any intervention carried out in naturalistic educational settings, there are limitations of the current study. One limitation was the relatively small sample size. Although many social-psychological interventions have been successful with small samples, we suspect that the limited number of participants in this study contributed to insufficient power needed to detect differences between the groups on some variables. Studies with smaller sample sizes lend themselves to type II error -- incorrectly accepting the null hypothesis and assuming no significant effects when effects do in fact exist (Murphy \& Myors, 2004). Although the results of the intervention are promising, scaling up is necessary for increased strength of interpretation of the findings.

A second limitation, which is also related to completing experimental studies in natural settings, is the inability to take into account the variety of contextual factors that may impact the ability to detect the intervention's effectiveness. Research has shown that contextual factors, such as influences from home, school, and peers, can have an impact on student motivation and achievement (Deci, Vallerand, Pelletier \& Ryan, 1991; Miller \& Brickman, 2004; Guay \& Vallerand, 1997). Although measures were taken to minimize circumstantial influences (e.g., controlled design, selection criteria, treatment fidelity measures), it is possible that teacher ratings in particular were less responsive to reflecting (short term) change against a backdrop of deep-seated beliefs regarding student characteristics and behaviors (Oates, 2003; Seyfried, 1998). The important issue of acknowledging and honoring positive change in students with a history of low achievement or antisocial behaviors has been a focus in past intervention efforts (e.g., Graham, et al., 2015).

A third limitation of this study was the lack of measures that could explore an underlying objective of attribution retraining interventions. Measures that were used in this study focused on the perception of effort (vs. ability) as a cause for an experienced past failure. This methodological decision allowed fundamental comparisons with past literature to be made, however a key focus of this and indeed other attribution retraining studies in general, is on behavioral effort and preparation as an avenue for improving academic outcomes in the future. Items like "I should have studied more" and "I didn't try hard enough" express beliefs about past failure, but do not explicitly assess beliefs about the benefits of increased effort related to future outcomes. Longitudinal investigations and measurement tools that are more future-oriented are warranted to better address the implicit long-term goals of attribution retraining studies. Modified academic self-efficacy items such as "I can do better, if I try harder" or "I can do almost all the work, if I don't give up" could examine the basic core of achievement-related attribution retraining interventions and would more effectively help to identify whether students view increasing effort as a strategy for changing unwanted academic outcomes in the future (Midgley et al., 2000).

\subsection{Implications for Policy and Practice}

This study focused on students' own personal attitudes and beliefs regarding an experienced academic failure. From a policy perspective, this study highlights the value of student voice and the need for students' perspectives to be included in the ongoing discussions and conversations surrounding how to improve the outcomes of African American youth. This intervention incorporated elements important in programming designed for urban African American youth. The lessons presented in the current intervention were culturally specific and included the use of same-race role models to help students connect to the messages provided and aid them in creating stronger bonds and trust with mentors (Hurd, Sanchez, Zimmerman \& Caldwell, 2012: Lee, 1999, Miranda et al., 2005). Researchers have noted that successful interventions for at-risk minorities (especially African-American youth) 
should be culturally sensitive and designed with the targeted population in mind (Graham, et al., 2003; LaPoint et al., 2006; Miranda et al., 2005; Tucker \& Herman, 2002). Thus, the use of culturally relevant components as well as the unique opportunity for students to acknowledge attributions to discrimination, may have contributed to the success of this intervention. With modifications that address cultural differences, this intervention may also be beneficial to middle school students in other racial/ethnic groups who are struggling academically with the transition to middle school.

In short, this intervention curriculum offers a model for educators to encourage positive thinking about school and goal setting particularly for African-American males. In addition to offering materials that are appropriate for the population being studied, the intervention also offers simple and socially acceptable activities that teachers can use to support students who may be at risk for academic failure.

\section{Conclusion}

In an aim to foster adaptive behaviors and improve academic outcomes for African-American youth, the current study incorporated students' voices and perceptions into a brief school-based intervention program. Many researchers have suggested the need for a new approach to addressing the ongoing achievement gap - one that incorporates the often-omitted perspectives of students on these issues (Cook-Sather, 2006; Nieto, 1994). One of the primary focuses of this study was to understand how African-American students' personal beliefs about the causes of their academic failures could be used to reframe their academic cognition and behaviors. This study provides preliminary evidence that through better understanding African-American students' beliefs about their academic failures and success, educators can begin to formulate strategies and plans that can help improve the educational outcomes for these youth. Overall, this study gives promise that evidence-based interventions can be adapted to address the specific issues confronting African-American students before the critical transition to middle school. However, there is still much to understand in terms of gender differences and translating changes in students' academic-related cognition to key and necessary changes in academic behaviors.

\section{Acknowledgements}

This research was supported by grants from the University of California, All Campus Consortium on Research for Diversity (UC/ACCORD), and the Society for the Psychological Study of Social Issues. The authors want to also acknowledge Dr. Sandra Graham (University of California, Los Angeles) for her ongoing support, guidance and advice on the attribution retraining intervention design and implementation. We also acknowledge the enthusiastic participation of the schools, teachers, students, and undergraduate research assistants that were a part of this study. Without your participation this program would not have been possible.

\section{References}

Anderman, E. M., Maehr, M. L., \& Midgley, C. (1999). Declining motivation after the transition to middle school: Schools can make a difference. Journal of Research \& Development in Education, 32, 131-147.

Aronson, J., Fried, C. B., \& Good, C. (2002). Reducing the effects of stereotype threat on African American college students by shaping theories of intelligence. Journal of Experimental Social Psychology, 38, 113-125. https://doi.org/10.1006/jesp.2001.1491

Bandura, A. (1997). Self-efficacy: The exercise of control. New York: W. H. Freeman \& Company.

Barton, P. (2003). Parsing the Achievement Gap. Princeton, NJ: Educational Testing Service.

Blackwell, L. A., Trzesniewski, K. H., \& Dweck, C. S. (2007). Implicit theories of intelligence predict achievement across the junior high school transition: A longitudinal study and an intervention. Child Development, 78, 246-263. https://doi.org/10.1111/j.1467-8624.2007.00995.x

Boykin, A. W., \& Noguera, P. (2011). Creating the opportunity to learn. Alexandria, VA: Association for Supervision and Curriculum Development.

Caldas, S. J. (1993). Reexamination of input and process factor effects on public school achievement. The Journal of Educational Research, 86(4), 206-214. https://doi.org/10.1080/00220671.1993.9941832

Cohen, J. (1988). Statistical power analysis for the behavioral sciences. San Diego, CA: Academic Press.

Cook-Sather, A. (2006). Sound, presence, and power: "Student voice" in educational research and reform. Curriculum Inquiry, 36(4), 359-390. https://doi.org/10.1111/j.1467-873X.2006.00363.x

Crocker, J., \& Major, B. (1989). Social stigma and self-esteem: The self-protective properties of stigma. Psychological Review, 96, 608-630. https://doi.org/10.1037/0033-295X.96.4.608

Darling-Hammond, L. (2007). Third annual Brown lecture in education research-The flat earth and education: 
How America's commitment to equity will determine our future. Educational Researcher, 36(6), 318-334. https://doi.org/10.3102/0013189X07308253

Deci, E. L., Vallerand, R. J., Pelletier, L. G., \& Ryan, R. M. (1991). Motivation in education: The self-determination perspective. The Educational Psychologist, 26, 325-346. https://doi.org/10.1207/s15326985ep2603\&4_6

Ensminger, M. E., Forrest, C. B., Riley, A. W., Kang, M., Green, B. F., Starfield, B., \& Ryan, S. A. (2000). The validity of measures of socioeconomic status of adolescents. Journal of Adolescent Research, 15(3), 392-419. https://doi.org/10.1177/0743558400153005

Ford, D. Y. (1992). The American achievement ideology as perceived by urban African-American students' exploration by gender and academic program. Urban Education, 27(2), 196-211. https://doi.org/10.1177/0042085992027002006

Ford, D. Y., \& Moore, J. L. (2013). Understanding and reversing underachievement, low achievement, and achievement gaps among high-ability African American males in urban school contexts. The Urban Review, 45(4), 399-415. https://doi.org/10.1007/s11256-013-0256-3

Freire, P. (2000). The pedagogy of the oppressed (3rd ed.). New York: Continuum.

Good, C., Aronson, J., \& Inzlicht, M. (2003). Improving adolescents' standardized test performance: An intervention to reduce the effects of stereotype threat. Journal of Applied Developmental Psychology, 24(6), 645-662. https://doi.org/10.1016/j.appdev.2003.09.002

Graham, S. (1984). Communicating sympathy and anger to black and white children: The cognitive (attributional) antecedents of affective cues. Journal of Personality and Social Psychology, 47, 40-54. https://doi.org/10.1037/0022-3514.47.1.40

Graham, S. (1994). Motivation in African Americans. Review of Educational Researcher, 64(1), 55-117. https://doi.org/10.2307/1170746

Graham, S. (2016). An attributional perspective on motivation in ethnic minority youth. In J. DeCuir-Gunby, \& P. Schutz (Eds.), Race and ethnicity in the study of motivation in education (pp. 13-35). New York: Routledge.

Graham, S., \& Hudley, C. (2005). Race and ethnicity in the study of motivation and competence. In C. Dweck, \& A. Elliott (Eds.), Handbook of motivation and competence. New York: Guilford Press.

Graham, S., \& Weiner, B. (1993). Attributional applications in the classroom. In T. Tomlinson (Ed.), Motivating students to learn: Overcoming barriers to high achievement (pp. 179-196). Berkeley, CA: McCutchen.

Graham, S., Taylor, A., \& Dolland, C. (2003). A motivation intervention for at-risk youth. In F. Salili, \& R. Hoosain (Eds.), Teaching, learning, and motivation in a multicultural context. Greenwich, CT: Information Age Publishing.

Graham, S., Taylor, A., \& Hudley, C. (2015). A motivational intervention for African American boys labeled as aggressive. Urban Education, 50(2), 194-224. https://doi.org/10.1177/0042085914549364

Guay, F., \& Vallerand, R. J. (1997). Social context, student's motivation, and academic achievement: Toward a process model. Social Psychology of Education, 1, 211-233. https://doi.org/10.1007/BF02339891

Haynes, T. L., Perry, R. P., Stupnisky, R. H., \& Daniels, L. M. (2009). A review of attributional retraining treatments: Fostering engagement and persistence in vulnerable college students. In J. Smart (Ed.), Higher education: Handbook of theory and research (pp. 227-272). https://doi.org/10.1007/978-1-4020-9628-0_6

Howard, T. C. (2014). Black male(d): Peril and promise in the education of African American males. New York, NY: Teachers College Press.

Hudley, C. (2001, April). Perceived behavioral and academic competence in middle childhood: Influences of a community-based youth development program. Paper presented at the meeting of American Educational Research Association, Seattle, $\quad$ Retrieved from http://www.eric.ed.gov/ERICDocs/data/ericdocs2/content_storage_01/0000000b/80/25/91/ff.pdf

Hughes, D., Rodriguez, J., Smith, E. P., Johnson, D. J., Stevenson, H. C., \& Spicer, P. (2006). Parents' a cial/ethnic socialization practices: A review of research and agenda for future study. Developmental Psychology, 42(5), 747-770. https://doi.org/10.1037/0012-1649.42.5.747 
Hurd, N. M., Sánchez, B., Zimmerman, M. A., \& Caldwell, C. H. (2012). Natural mentors, racial identity, and educational attainment among African American adolescents: Exploring pathways to success. Child Development, 83(4), 1196-1212. https://doi.org/10.1111/j.1467-8624.2012.01769.x

IRRE. (1998). Research assessment package for schools (RAPS) manual. Philadelphia: Institute for Reform and Research in Education. $\quad$ Retrieved from https://morandissertation.files.wordpress.com/2013/01/raps_manual_entire_19981.pdf

Irving, M. A., \& Hudley, C. (2008). Cultural identification and academic achievement among African American males. Journal of Advanced Academics, 19(4), 676-698. https://doi.org/10.4219/jaa-2008-833

Jencks, C., \& Phillips, M. (1998). The Black-White test scope gap. Washington DC: Brookings Institute.

Johnson, V. C. (2002). Black power in the suburbs: The myth or reality of African American suburban political incorporation. Albany, NY: State University of New York Press.

Kratochwill, T. R., \& Stoiber, K. C. (2000). Empirically supported interventions and school psychology: Conceptual practices issue - Part II. School Psychology Quarterly, 15(2), $233-253$. https://doi.org/10.1037/h0088786

LaPoint, V., Ellison, C. M., \& Boykin, A. W. (2006). Educating the whole child: The talent quest model for educational policy and practice. The Journal of Negro Education, 373-388.

Lee, W. Y. (1999). Striving toward effective retention: The effect of race on mentoring African American students. Peabody Journal of Education, 74(2), 27-43. https://doi.org/10.1207/s15327930pje7402_4

Major, B., Quinton, W. J., \& Schmader, T. (2003). Attribution of discrimination and self-esteem: Impact of group identification and situational ambiguity. Journal of Experimental Social Psychology, 39, $220-231$. https://doi.org/10.1016/S0022-1031(02)00547-4

Midgley, C., Maehr, M. L., Hruda, L., Anderman, E. M., Anderman, L., Freeman, K. E., ... Urdan, T. (2000). Manual for the patterns of adaptive learning scales (PALS). Ann Arbor, MI: University of Michigan. Retrieved from http://www.umich.edu/ pals/pals/PALS\%202000_V13Word97.pdf

Miller, R. B., \& Brickman, S. J. (2004). A model of future-oriented motivation and self-regulation. Educational Psychology Review, 16(1), 9-33. https://doi.org/10.1023/B:EDPR.0000012343.96370.39

Miranda, J., Bernal, G., Lau, A., Kohn, L., Hwang, W., \& LaFramboise, T. (2005). State of the science on psychosocial interventions for ethnic minorities. Annual Review in Clinical Psychology, 1, 113-142. https://doi.org/10.1146/annurev.clinpsy.1.102803.143822

Murphy, K. R., \& Myors, B. (2004). Statistical power analysis: A simple and general model for traditional and modern hypothesis tests (2nd ed.). Mahwah, NJ: Lawrence Erlbaum Associates.

Nieto, S. (1994). Lessons from students on creating a chance to dream. Harvard Educational Review, 63(4), 392-426.

Oates, G. L. S. C. (2003). Teacher-student racial congruence, teacher perceptions, and test performance. Social Science Quarterly, 84(3), 508-525. https://doi.org/10.1111/1540-6237.8403002

Ogbu, J. U. (1991). Minority Coping Responses and School Experiences. The Journal of Psychohistory, 18(4), 433-456.

Perry, R. P., Stupnisky, R. H., Hall, N. C., Chipperfield, J. G., \& Weiner, B. (2010). Bad starts and better finishes: Attributional retraining and initial performance in competitive achievement settings. Journal of Social and Clinical Psychology, 29, 668-700. https://doi.org/10.1521/jscp.2010.29.6.668

Robertson, J. S. (2000). Is attribution training a worthwhile classroom intervention for K-12 students with learning difficulties?. Educational Psychology Review, 12(1), 111-134. https://doi.org/10.1023/A:1009089118008

Sanders, M. G. (1998). The effects of school, family, and community support on the academic achievement of African American adolescents. Urban Education, 385-409. https://doi.org/10.1177/0042085998033003005

Seaton, E. K., Caldwell, C. H., Sellers, R. M., \& Jackson, J. S. (2008). The prevalence of perceived discrimination among African American and Caribbean Black youth. Developmental Psychology, 44, 1288-1297. https://doi.org/10.1037/a0012747

Seyfried, S. F. (1998). Academic achievement of African American preadolescents: The influence of teacher perceptions. American Journal of Community Psychology, 26(3), 381-402. 
https://doi.org/10.1023/A:1022107120472

Simmons, R. G., Black, A., \& Zhou, Y. (1991). African-American versus White Children and the Transition into Junior High School. American Journal of Education, 99(4), 481-520. https://doi.org/10.1086/443995

Smalls, C., White, R., Chavous, T., \& Sellers, R. (2007). Racial ideological beliefs and racial discrimination experiences as predictors of academic engagement among African American adolescents. Journal of Black Psychology, 33(3), 299-330. https://doi.org/10.1177/0095798407302541

Snyder, C. R., Hoza, B., Pelham, W. E., Rapoff, M., Ware, L., Danovsky, M., et al.. (1997). The development and validation of the children's hope scale. Journal of Pediatric Psychology, 22(3), 399-421. https://doi.org/10.1093/jpepsy/22.3.399

Steele, C. (1992). Race and schooling of black Americans. The Atlantic Monthly 269: 791-798. Retrieved from https://www.theatlantic.com/magazine/archive/1992/04/race-and-the-schooling-of-black-americans/306073/

Swinton, A. D., Kurtz-Costes, B., Rowley, S. J., \& Okeke-Adeyanju, N. (2011). A longitudinal examination of African American adolescents' attributions about achievement outcomes. Child Development, 82(5), 1486-1500. https://doi.org/10.1111/j.1467-8624.2011.01623.x

Tatum, A. W. (2005). Teaching reading to African American adolescent males: Closing the achievement gap. Portland, ME: Stenhouse.

Taylor, A. Z., \& Graham, S. (2007). An examination of the relationship between achievement values and perceptions of barriers among Low-SES African American and Latino students. Journal of Educational Psychology, 99(1). https://doi.org/10.1037/0022-0663.99.1.52

Tucker, C. M., \& Herman, K. C. (2002). Using culturally sensitive theories and research to meet the academic needs of low-income African American children. American Psychologist, 57(10), 762-773. https://doi.org/10.1037/0003-066X.57.10.762

United States Department of Education. (2009a). National Center for Education Statistics. National Assessment of Educational Progress (NAEP) 2009 Reading Assessment. Washington, DC: Author.

United States Department of Education. (2009b). National Center for Education Statistics. National Assessment of Educational Progress (NAEP) 2009 Mathematics Assessment. Washington, DC: Author.

United States Department of Education. (2015). National Center for Education Statistics. NAEP Reading and Mathematics 2015 Results. Washington, DC: Author. Retrieved from $\mathrm{http} / / /$ www.nationsreportcard.gov/reading_math_2015/\#mathematics?grade=4

Van Laar, C. (2000). The paradox of low academic achievement but high self-esteem in African American students: an attributional account. Educational Psychology Review, 12(1), 33-61. https://doi.org/10.1023/A:1009032900261

Vaughn, S., Denton, C. A., \& Fletcher, J. M. (2010). Why intensive interventions are necessary for students with severe reading difficulties. Psychology in the Schools, 47(5), 432-444. https://doi.org/10.1002/pits.20481

Weiner, B. (1985). Human motivation. New York: Springer-Verlag.

Weiner, B. (1995). Judgments of responsibility: A foundation for a theory of social conduct. New York: Guilford Press.

Weiner, B. (2000). Intrapersonal and interpersonal theories of motivation from an attributional perspective. Educational Psychology Review, 12(1), 1-14. https://doi.org/10.1023/A:1009017532121

Wellborn, J. G., \& Connell, J. P. (1991). Engagement Versus Disaffection: Motivated Patterns of Action in the Academic Domain. Rochester, NY: University of Rochester.

Wigfield, A., Lutz, S. L., \& Wagner, A. L. (2005). Early adolescents' development across the middle school years: Implications for school counselors. Professional School Counseling, 9(2), 112-119. https://doi.org/10.5330/prsc.9.2.2484n0j255vpm302

Willig, A., Harnisch, D., Hill, K., \& Maehr, M. (1983). Sociocultural and educational correlates of success-failure attributions and evaluation anxiety in the school setting for black, Hispanic, and Anglo children. American Educational Research Journal, 20, 385-410. https://doi.org/10.2307/1162607

Wilson, T. D., \& Linville, P. W. (1982). Improving the academic performance of college freshmen: Attribution therapy revisited. Journal of Personality and Social Psychology, 42(2), 367-376. https://doi.org/10.1037/0022-3514.42.2.367 
Wilson, T. D., \& Linville, P. W. (1985). Improving the performance of college freshmen with attributional techniques. Journal of Personality and Social Psychology, 49(1), $287-293$. https://doi.org/10.1037/0022-3514.49.1.287

Wilson, T. D., Damiani, M., \& Shelton, N. (2002). Improving the academic performance of college students with brief attributional interventions. In J. Aronson (Ed.), Improving academic achievement (pp. 89-108). Academic Press. https://doi.org/10.1016/B978-012064455-1/50008-7

Wong, C. A., Eccles, J. S., \& Sameroff, A. (2003). The influence of ethnic discrimination and ethnic identification on African American adolescents' school and socioemotional adjustment. Journal of Personality, 71(6), 1197-1232. https://doi.org/10.1111/1467-6494.7106012

Wood, D., Kaplan, R., \& McLoyd, V. C. (2007). Gender difference in the educational expectations of urban, low-income African American youth: The role of parents and the school. Journal of Youth and Adolescence, 36(4), 417-427. https://doi.org/10.1007/s10964-007-9186-2

Wyman, E. L., Cowen, W. C., \& Kerley, J. H. (1993). The role of children's future expectations in self-esteem function and adjustment to life stress: A prospective study of urban at risk children. Development and Psychopathology, 5, 649-661. https://doi.org/10.1017/S0954579400006210

Yaffe, D. (2012). Middle school matters: Improving the life course of Black boys. Educational Testing Service Policy Notes, 20(4). Retrieved from https://www.ets.org/Media/Research/pdf/PICPNV20n4.pdf

\section{Note}

Note 1. Although a standard alpha of .05 was used in testing hypotheses for treatment effects, due to the small sample size, results approaching significance were also considered. Small sample sizes have the tendency to increase the chance of incorrectly accepting the null hypothesis because they often require large effects for any results to be significant. Previous social behavioral interventions have repeatedly shown small effects, thus statisticians have suggested using a more lenient alpha when working with small samples (Murphy \& Myors, 2004).

\section{Copyrights}

Copyright for this article is retained by the author(s), with first publication rights granted to the journal.

This is an open-access article distributed under the terms and conditions of the Creative Commons Attribution license (http://creativecommons.org/licenses/by/4.0/). 